\title{
Date and Time of Informed Consent
}

National Cancer Institute

\section{Source}

National Cancer Institute. Date and Time of Informed Consent. NCI Thesaurus. Code C117452.

The date and time of informed consent collection. 